World Neurosurg. 2013 November ; 80(5): . doi:10.1016/j.wneu.2012.05.014.

\title{
Re-Engineering the Subthalamus
}

\author{
Dennis A. Turner, MA, MD [Professor] \\ Neurosurgery and Neurobiology, Duke University Medical Center Durham, NC 27710
}

\begin{abstract}
This historical vignette of the region known as "subthalamus" is timely and brings up how our current concepts regarding this region have evolved into the current level of high clinical importance for clinical treatment schemes. This pertinent review of older literature (particularly prior to 1990) highlights how previous concepts as to functioning and treatment in this region have been redefined and improved (1). Whereas most efforts at treatment of this region are now focused on motor disorders (ie, tremor and Parkinson's disease) this vignette outlines the wide variety of other disorders once considered as involving the subthalamus, including epilepsy (16), chronic pain, and behavioral disorders, as neurosurgeons experimented to define the function of this region. Additionally, the authors include previous treatment paradigms (ie, various forms of lesioning, the previous mainstay of generating a treatment effect), now mostly supplanted by long-term electrical stimulation with deep brain stimulation (DBS), gene therapy approaches to modify long-term cellular function, and other biological or cellular treatments, all focused on augmentation of function rather than lesioning.
\end{abstract}

Defined roughly as the diencephalic region below the AC-PC line (hence ventral to the thalamus), medial to the internal capsule/cerebral peduncle, lateral to the hypothalamus and bordering the mesencephalon, there are multiple structures within this small region (3). Nuclei included are the subthalamic nucleus (STN), zona incerta and nuclei of the tegmental fields of Forel, whereas fiber bundles traversing the region include the ascending cerebellar tracts coursing into the ventral intermediate nucleus (Vim) of the thalamus (15), the medial lemniscus ascending into the ventrocaudal (Vc, sensory) nucleus, and the ansa lenticularis as the main fiber output bundle from globus pallidus interna (GPi) terminating in ventral motor thalamus (ie, Voa, Vop). However, directly bordering this region are multiple additional structures, many of which are functionally connected, particularly substantia nigra pars reticulata $(\mathrm{SNr})$ and pedunculopontine nucleus (PPN), which are also considered in this vignette.

Neurosurgeons have been at the forefront of exploration of this (and other adjacent deep brain regions) due to the clinical impetus for treating a wide range of disorders for which (at one time) surgery was the primary option (1). However, in practice stereotactic surgery often demonstrated higher risk, less efficacy, and more ethical dilemmas than initially expected $(1,13)$, along with high targeting variability between patients from ventriculography alone, during the 1960's and 1970's in particular. Concurrently medical treatment was improving, beginning with antipsychotics and better anticonvulsants in the 1950's (9) and L-dopa and carbidopa in the 1960's (8), so that stereotactic treatment options were reduced to primarily

\footnotetext{
(c) 2012 Elsevier Inc. All rights reserved.

correspondence to: Dennis A. Turner MA, MD, Box 3807, NSU, DUMC, Durham, NC 27710, dennis.turner@ duke.edu, phone 919-684-6706, FAX 919-681-8068.

Publisher's Disclaimer: This is a PDF file of an unedited manuscript that has been accepted for publication. As a service to our customers we are providing this early version of the manuscript. The manuscript will undergo copyediting, typesetting, and review of the resulting proof before it is published in its final citable form. Please note that during the production process errors may be discovered which could affect the content, and all legal disclaimers that apply to the journal pertain.
} 
thalamic treatment of refractory tremor by the 1970's (1). Thus, very few of the exploratory treatment options refined by neurosurgeons after the advent of stereotactic approaches in 1949 continued to be valid treatment options (1), though concepts of human neuroanatomy and interpatient variability were extensively improved by these human exploratory procedures.

Fortunately, much of this rich past has now been resurrected with novel neurobiology concepts and new treatment approaches, as well as adapting the venerable ventriculographyguided stereotactic instruments (ie, Leksell frame in particular) to advanced imaging techniques (ie, MRI and CT) (1). For example, in the 1980's image-directed stereotactic biopsy became a significant improvement over open biopsy, then the first, crude version of DBS from the 1970's was extensively adapted to treatment of movement disorders, initially tremor (1). MPTP was accidentally discovered, leading to improved non-human primate models of Parkinsonism, and hence description of the critical role of subthalamic nucleus (STN) in Parkinson's disease (2). The convergence of these two advances in accurate stereotactic targeting and neurobiological underpinnings has led to the highly successful approach of STN DBS, now the gold standard of treatment of Parkinson's disease after medical management has started to wane. The knowledge of white matter in the subthalamus also remains relevant, as many neurosurgeons continue to leave an STN DBS contact within the Fields of Forel and lenticular fasiculus superficial to STN, because this contact activating pallidofugal fibers continues to be useful clinically.

Further, the description of CNS growth factors (based on the NGF prototype) has led (in the early 1990's) to development of variously differentiated CNS stem cells and identification of crucial growth factors leading to induction and maintenance of specific CNS cell types, particularly GDNF and neurturin for dopaminergic cells; these specific dopamine neuronal growth factors have now been tried in intraventricular form, direct putaminal infusion (11), and gene therapy approaches (4). Further, the possibility of viral-based gene therapy has also been tried in co-opting the primary glutaminergic (excitatory) basis of STN to GABAergic (inhibitory) function using GAD, the synthesizing enzyme for GABA (12). Even newer neurobiological approaches have started to define the role of STN in Parkinson's disease, particularly the important role of motor cortex collaterals to STN, using optogenetic approaches (6). STN may also be useful for implementation of a subcortical brain-machine interface (BMI), due to its optimal location at the convergence of motor systems $(7,14)$. Further, continued research on mechanisms of brain function from intra-operative and postoperative studies flourishes (17), fostering rapid advances in both understanding of the structures being analyzed and treatment routes involving these structures.

In the long quest to both improve subcortical function in a variety of diseases and to analyze function of this difficult to access region, neurosurgeons have continued to take a pivotal role in describing both physiological function of human brain as well as defining therapeutic approaches. In our current search for new therapeutic targets which might transcend the limitations of available therapy sometimes reinvigorating an old site makes considerable sense. This was the case of Laitenen's further description of Leksell's older cases of ventral pallidal lesioning for Parkinson's: these patients quietly did well for many years before a reexamination revealed long-term efficacy in Parkinson's disease (10). Most available therapeutic targets have either derived from older concepts of brain function (through lesions) or from "designer" surgery based on new scientific approaches. The latter includes the preclinical description of the effects of STN lesions in MPTP non-human primates (2) as well as the functional imaging studies pointing to subcallosal frontal lobe involvement (ie, Area 25) in the treatment of refractory depression (13). Most other targets are based on older lesion data, including thalamic DBS for tremor (1), anterior thalamic DBS for epilepsy (5), pallidal DBS for Parkinson's (10), and anterior limb internal capsule DBS for depression/ 
OCD (13). Thus, occasionally a study of an older target can be revived with new techniques (ie, DBS instead of lesion) or new insights into connectivity, and refined for future therapeutic approaches.

This review of stereotactic surgery is timely and overall helpful to the literature. For example, SNr is clear involved with epilepsy (16) and STN interventions to treat seizures have not worked well, particularly in contrast to anterior thalamus. Behavioral disorders (ie, depression, OCD) are treated in areas either recently defined (ie, Area 25) or in more traditional frontal lobe connection regions originally described as replacement for the crude frontal lobotomy procedure (ie, cingulotomy, subcaudate tractotomy and anterior internal capsule lesions) (13). Treatment of chronic pain with sensory (ie, Vc) thalamic stimulation and peri-acqueductal gray (PAG) stimulation was withdrawn by 1980, and there has been only mild interest in its revival, in spite of the clear parallel between $\mathrm{Vc}$ /medial lemniscus stimulation for facial pain and spinal cord stimulation for extremity pain. Thus, this small area of the diencephalon demonstrates a colorful past, an active present and a considerable future, re-engineering the interactions of neurosurgical experimentation with new techniques and neurobiological approaches.

\section{Acknowledgments}

Supported by NIH Grants R21NS06611 and R01AG037599 and a VA Merit Review Award.

\section{References}

1. Benabid AL, Chabardes S, Torres N, Piallat B, Krack P, Fraix V, Pollak P. Functional neurosurgery for movement disorders: a historical perspective. Prog Brain Res. 2009; 175:379-391. [PubMed: 19660668]

2. Bergman H, Wichmann T, DeLong MR. Reversal of experimental Parkinsonism by lesions of the subthalamic nucleus. Science. 1990; 249:1436-1438. [PubMed: 2402638]

3. Carpenter, MB.; Sutin, J. Human Neuroanatomy. Baltimore: Williams and Wilkins; 1983.

4. Ceregene PD Neurturin Study Group. Gene delivery of AAV2-neurturin for Parkinson's disease: a double-blind, randomized controlled trial. Lancet Neurology. 2010; 9:1164-1172. [PubMed: 20970382]

5. Fisher R, Salanowa V, Witt T, Worth R, Henry T, Gross R, Oommen K, Osorio I, Nazzaro J, Labar D, Kaplitt M, Sperling M, Sandok E, Neal J, Handforth A, Stern J, DeSalles A, Chung S, Shetter A, Bergen D, Bakay R, Henderson J, French J, Baltuch G, Rosenfeld W, Youklis A, marks W, Garcia P, Barbaro N, fountain N, Basil C, Goodman R, McKhann G, babu Krishnamurthy K, Papawassiliou S, Epstein C, Pollard J, Tonder L, Grebin J, Coffey R, Graves N. SANTE Study Group. electrical stimulation of the anterior nucleus of thalamus for treatment of refractory epilepsy. Epilepsia. 2010; 51:899-908. [PubMed: 20331461]

6. Gradinaru V, Mogri M, Thompson KR, Henderson JM, Deisseroth K. Optical deconstruction of Parkinsonism neural circuitry. Science. 2009; 324:354-359. [PubMed: 19299587]

7. Hanson T, Fuller AM, Lebedev MA, Turner DA, Nicolelis MAL. Subcortical neuronal ensembles: an analysis of motor task association, tremor, oscillations and synchrony in human patients. J Neuroscience. 2012 in press.

8. Hornykiewicz O. L-Dopa: from a biologically inactive amino acid to a successful therapeutic agent. Amino Acids. 2002; 23:65-70. [PubMed: 12373520]

9. Kane JM, Correll CU. Past and present progress in the pharmacologic treatment of schizophrenia. J Clin Psychiatry. 2010; 71:1115-1124. [PubMed: 20923620]

10. Laitenen LV, Bergenheim AT, Hariz MI. Leksell's posteroventral pallidotomy in the treatment of Parkinson's disease. J Neurosurg. 1992; 76:53-61. [PubMed: 1727169]

11. Lang AE, Gill S, Patel NK, Lozano A, Nutt JG, Penn R, Brooks DJ, Hotton G, Moro E, Heywood P, Brodsky MA, Burchiel K, Hutchinson M, Kelly P, Dalvi A, Scott B, Stacy M, Turner D, Wooten GF, Elias WJ, Laws ER, Dhawan V, Stoessl AJ, Matcham J, Coffey RJ, Traub M. 
Randomized Controlled Trial of Intraputamenal Glial Cell Line-Derived Neurotrophic Factor Infusion in Parkinson Disease. Annals of Neurology. 2006; 59:459-466. [PubMed: 16429411]

12. LeWitt PA, Rezai AR, Leehey MA, Ojemann SG, Flaherty AW, Eskandar EN, Kostyk SK, Thomas K, Sarkar A, Siddiqui MS, Tatter SB, Schwalb JM, Poston KL, Hnderson JM, Kurlan RM, Richard IH, Van Meter L, Sapan CV, During MJ, Kaplitt MG, Feigin A. AAV2-GAD gene therapy for advanced Parkinson's disease: a double-blind, sham surgery controlled, randomized trial. Lancet Neurol. 2011; 10:309-319. [PubMed: 21419704]

13. Mashour GA, Walker EE, Martuza RL. Psychosurgery: past, present and future. Brain Res Brain Res Rev. 2005; 48:409-419. [PubMed: 15914249]

14. Patil PG, Carmena J, Nicolelis MAL, Turner DA. Ensemble recordings of human subcortical neurons as a source of motor control signals for a brain-machine interface. Neurosurgery. 2004; 55:27-38. [PubMed: 15214971]

15. Sedrak M, Gorgulho A, Frew A, Behnke E, DeSalles A, Pouratian N. Diffusion tensor imaging and fractional anisotropy mapping of the Vim thalamus. Neurosurgery. 2011; 69:1124-1129. [PubMed: 21697755]

16. Veliskova J, Moshe SL. Update on the role of substantia nigra pars reticulate in the regulation of seizures. Epilepsy Curr. 2006; 6:83-87. [PubMed: 16761069]

17. Zaghloul KA, Blanco JA, Weidemann CT, McGill K, Jaggi JL, Baltuch GH, Kahana MJ. Human substantia nigra neurons encode unexpected financial rewards. Science. 2009; 323:1496-1499. [PubMed: 19286561] 